ARTICLE

Received 10 Sep 2012 | Accepted 15 Nov 2012 | Published 18 Dec

DOI: $10.1038 /$ ncomms2308

OPEN

\title{
Transmembrane insertion of twin-arginine signal peptides is driven by TatC and regulated by TatB
}

Julia Fröbel ${ }^{1,2}$, Patrick Rose ${ }^{1,2}$, Frank Lausberg ${ }^{3}$, Anne-Sophie Blümmel ${ }^{1}$, Roland Freudl ${ }^{3}$ \& Matthias Müller ${ }^{1}$

The twin-arginine translocation (Tat) pathway of bacteria and plant chloroplasts mediates the transmembrane transport of folded proteins, which harbour signal sequences with a conserved twin-arginine motif. Many Tat translocases comprise the three membrane proteins Tat $\mathrm{A}$, Tat $\mathrm{B}$ and TatC. TatC was previously shown to be involved in recognizing twin-arginine signal peptides. Here we show that beyond recognition, TatC mediates the transmembrane insertion of a twin-arginine signal sequence, thereby translocating the signal sequence cleavage site across the bilayer. In the absence of TatB, this can lead to the removal of the signal sequence even from a translocation-incompetent substrate. Hence interaction of twin-arginine signal peptides with TatB counteracts their premature cleavage uncoupled from translocation. This capacity of TatB is not shared by the homologous TatA protein. Collectively our results suggest that TatC is an insertase for twin-arginine signal peptides and that translocation-proficient signal sequence recognition requires the concerted action of TatC and TatB.

\footnotetext{
${ }^{1}$ Institute of Biochemistry and Molecular Biology, ZBMZ, University of Freiburg, Stefan-Meier-Strasse 17 D-79104 Freiburg, Germany. ${ }^{2}$ Faculty of Biology, University of Freiburg, Schänzle-Strasse 1 D-79104 Freiburg, Germany. ${ }^{3}$ Institute of Bio- and Geosciences, IBG1: Biotechnology, Forschungszentrum Jülich GmbH, D-52425 Jülich, Germany. Correspondence and requests for materials should be addressed to M. M.

(email: matthias.mueller@biochemie.uni-freiburg.de).
} 
T win-arginine (Tat)-specific protein translocation machineries are found in bacteria, archaea and plant chloroplasts. Tat machineries have the remarkable property to transport fully folded proteins across cellular membranes. These proteins are specifically directed to the Tat pathway by signal peptides harbouring a conserved S-R-R-X-F-L-K sequence motif (RR-signal peptides). The current knowledge on the Tat pathway has comprehensively been reviewed ${ }^{1-5}$.

In Gram-negative bacteria and plant chloroplasts, Tat machineries are composed of three membrane proteins that in bacteria are termed TatA, TatB and TatC. TatA encompasses a single transmembrane domain and a cytosolically located amphipathic helix ${ }^{6,7}$ that is followed by an unstructured C-terminus. Despite contradictory reports in the past ${ }^{8-10}$, recent reports confirm an $\mathrm{N}_{\text {out }}$-orientation of the transmembrane helix of $\operatorname{Tat}^{11,12}$. The homologous, yet functionally distinct TatB subunit has the same predicted structure as TatA. TatC on the other hand, possesses six predicted transmembrane helices with the $\mathrm{N}$ - and $\mathrm{C}$-termini of the protein facing the cytoplasm. In E. coli, TatA is expressed at about 25- and 50-fold higher levels than TatB and TatC, respectively, but might be much less abundant in plant chloroplasts ${ }^{13}$. Two main complexes made up of the three Tat subunits have been described in E. coli: a $360-700 \mathrm{kDa}$ complex that is composed of oligomers of a 1:1 TatB/TatC core unit with varying amounts of TatA associated ${ }^{14,15}$, and an oligomeric TatA complex consisting of varying numbers of TatA protomers $(100-700 \mathrm{kDa})^{15-18}$.

The TatBC complex is involved in binding RR-signal peptides as shown by multiple experimental strategies, such as (1) interference of precursor binding to the Tat translocase by antibodies directed against TatB and $\mathrm{TatC}^{19}$, (2) comigration of precursor with a TatBC complex on Blue-native-polyacrylamide gel electrophoresis $(\mathrm{PAGE})^{20}$, (3) copurification of precursor, TatB and $\mathrm{Tat} C$ upon membrane solubilization ${ }^{16,21}$, (4) chemical and site-directed cross-linking $22-24$ and (5) identification of TatBC suppressor mutations of export-defective Tat signal peptides ${ }^{25,26}$.

The identification of binding sites both on TatBC, as well as on RR-signal peptides has been the subject of several reports. Thus crosslinking studies have repeatedly revealed a close proximity between the consensus RR-motif and $\mathrm{TatC}^{23,24,27}$. These signal peptide-TatC cross-links persist even in the absence of $\mathrm{TatB}^{23}$ pointing towards TatC as the primary recognition site for RRsignal sequences. Consistent with this notion, fusions between RR-signal peptides and PhoA were found to be redirected to the $\mathrm{Sec}$ translocon, if TatC was missing ${ }^{28}$. Using site-specific photo crosslinking the signal peptide-binding site of TatC was recently mapped to its cytosolic $\mathrm{N}$-terminus and first cytosolic loop ${ }^{29}$. In full agreement with these crosslinking studies, suppressor mutations in TatC that partially alleviate the transport block of KQ- and KK-mutant precursors map exactly to the same two domains of $\mathrm{TatC}^{25,30}$. Thus $\mathrm{TatC}$ provides a superficially exposed precursor recognition site.

The homooligomeric TatA complex forms pore-like structures $^{31}$, in which the transmembrane helices of TatA are arranged as rings ${ }^{32}$. These findings gave rise to a current model, according to which the TatA complexes represent individually form-fitting transmembrane conduits for folded Tat substrates. In this model, an RR-precursor following its binding to the TatBC complex would initiate the customized recruitment of Tat $\mathrm{A}$, a process that also requires the proton-motive force (PMF). Whether TatA is recruited only from membrane-integrated TatA protomers or also from a soluble pool of TatA is still an issue ${ }^{33}$.

Despite these insights there are a number of unsettled issues. Thus, some Tat-directed substrates might interact with the membrane bilayer before binding to TatBC ${ }^{34-36}$. Furthermore,
Tat transport was shown to proceed even in conditions, in which the Tat(A)BC and TatA complexes mentioned above could not be recovered to detectable levels, casting some doubt on those two complexes being true correlates of functional events during Tatdependent transport ${ }^{37}$. Similarly, enterobacteria contain an additional paralog of TatA, called TatE, that can functionally replace TatA although it forms much smaller complexes than TatA $^{38}$.

According to the above model, Tat $\mathrm{A}$ and TatB are predicted to fulfill quite diverse functions. In fact, single tat $A$ and tat $B$ knockout mutants of $E$. coli both show a tat phenotype despite a $20 \%$ sequence identity between both proteins. On the contrary, many Gram-positive bacteria naturally express only TatA and TatC orthologues. This suggests that in these organisms TatA has the functional roles of both TatA and TatB, which indeed could be verified experimentally ${ }^{39}$. Consistent with natural bifunctional TatA proteins, TatA variants that were altered at their extreme $\mathrm{N}$-termini have been isolated that are able to suppress a TatB deficiency in E. colit ${ }^{40}$. Here we experimentally exploited a TatB deficiency to unravel the unanticipated ability of TatC to act as a membrane insertase of Tat signal peptides.

\section{Results}

Correct cleavage of RR-precursors in the absence of TatB. Using the model Tat substrate TorA-MalE, distinct N-terminal mutations in tatA were previously isolated, that are able to suppress a complete lack of TatB in E. coli cells. These mutations render TatA a bifunctional TatA/B component ${ }^{37,40}$, much like in Gram-positive bacteria that naturally do not express a TatB subunit ${ }^{41}$. We were unable to detect the suppressing phenotype of those tat $A$ variants in vitro, probably because of the rather low overall translocation efficiency of our cell-free system. When performing these experiments we, however, noticed that E. coli membrane vesicles harbouring only TatC and TatA nevertheless led to a proteolytic processing of the TorA-MalE precursor.

This is shown in Fig. 1a that depicts the radiolabelled precursor TorA-MalE335 after in vitro synthesis in the absence or presence of TatABC- and TatAC-containing membrane vesicles. MalE is the periplasmic maltose-binding protein of $E$. coli, which naturally is exported through the Sec translocon but can be directed to the Tat system, if its Sec signal sequence is replaced by the RR-signal of the Tat substrate TMAO reductase (TorA $)^{42}$. Here we used the fusion protein TorA-MalE335 containing a C-terminally truncated MalEmoiety that lacks the inherent protease resistance of full-size MalE thereby allowing us to monitor its transport into membrane vesicles via protease protection. Thus TorA-MalE335 when synthesized by in vitro transcription/translation was completely digested by externally added proteinase K (PK; Fig. 1a, compare lanes 1 and 2). Following synthesis in the presence of inside-out inner membrane vesicles (INV) prepared from a TatABCDoverproducing E. coli strain (Tat ${ }^{+}$-INV), a significant amount of TorA-MalE335 was processed to a smaller species (lane 3). The processing product was resistant to PK (lane 4) suggesting that it had been translocated into the lumen of the vesicles and that it originated from cleavage by the vesicle-borne signal peptidase (leader peptidase). As usually observed for INV ${ }^{43}$, translocation was not strictly coupled to cleavage, because some of the precursor of TorA-MalE335 was also found to be PK-resistant (lane 4). This material was, however, slightly shorter than the non PK-treated precursor (compare lanes 3 and 4; see also figures below). We assume that this shift in molecular mass was due to a PK-mediated removal a few $\mathrm{N}$-terminal amino acids preceding the $\mathrm{RR}$-consensus motif from the otherwise membrane-protected TorA-signal peptide.

When instead INV were used that had been prepared from a strain only expressing TatA and TatC (Fig. 1b, lane 4) no PK- 
a

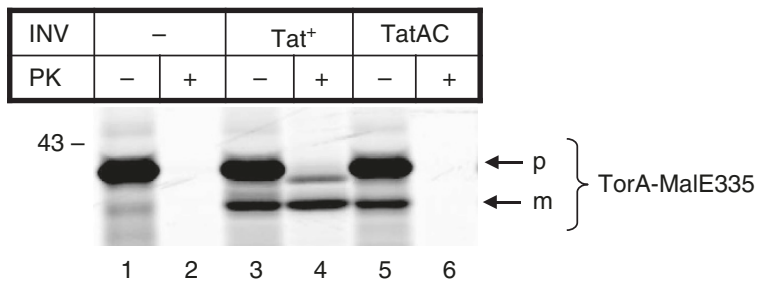

b

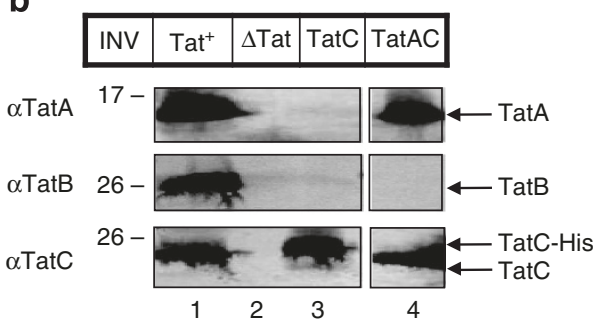

C

\begin{tabular}{|c|l|l|l|l|l|l|l|l|l|l|}
\hline INV & - & & \multicolumn{7}{|c|}{ TatAC } \\
\cline { 1 - 2 } Time (in min) & & & $1 / 2$ & 1 & 3 & 5 & 10 & 15 & 20 & 25 \\
\hline
\end{tabular}

d

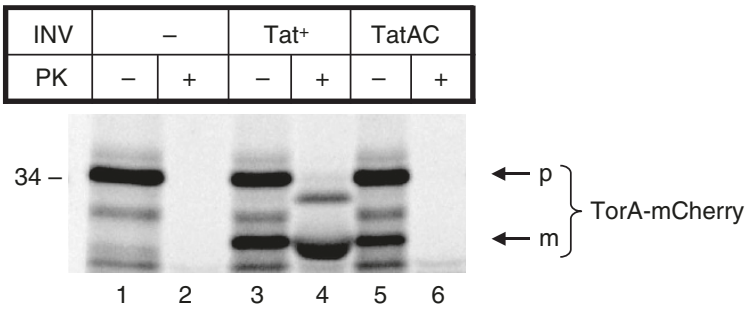

Figure 1 | Twin-arginine precursors are proteolytically processed in the absence of TatB. (a) The radiolabelled precursor TorA-MalE335 was synthesized in vitro by coupled transcription/translation in the absence or presence of TatABC- and TatAC-containing inside-out INV. Samples were digested with PK to visualize protease-resistant, that is, translocated, precursor $(p)$ and mature $(m)$ form of TorA-MalE335. Samples were separated by SDS-PAGE and visualized by phosphorimaging. Tat ${ }^{+}$-INV prepared from a TatABCD-overproducing E. coli strain show processing of the precursor of TorA-MalE335 and render its mature part and some precursor of slightly reduced size resistant to PK. In contrast, TatAC-INV prepared from a TatAC-overproducing $\Delta$ tat E. coli strain lacking TatB show a complete block in translocation, as no PK-resistant material was obtained. Nevertheless, these TatAC-INV proteolytically process TorA-MalE335 generating a fragment of the same electrophoretic mobility that mature TorA-MalE335 displays after its translocation into the Tat ${ }^{+}-$INVs. $_{\text {. }}$ (b) The indicated vesicles were dissolved in SDS-PAGE loading buffer and the Tat components were separated by SDS-PAGE and visualized by western blotting using polyclonal antibodies against TatA, TatB or TatC. Note that TatC-INV were prepared from a $\Delta$ tat strain expressing a His-tagged version of TatC. (c) TorA-MalE335 was synthesized for $10 \mathrm{~min}$. TatAC-INV were added and incubations stopped at the indicated times by adding TCA. Cleavage of TorA-MalE in the absence of TatB thus turned out to be a time-dependent process. (d) As in (a) using the Tat model precursor TorA-mCherry. As observed for TorA-MalE, the TatB-lacking TatAC-INV are not able to translocate TorA-mCherry, although they cause its proteolytic processing.

resistant material was obtained (Fig. 1a, lane 6), confirming a complete block in translocation when the TatB component was missing. Despite their translocation deficiency, these vesicles led to a substantial proteolytic processing of TorA-MalE335 (Fig. 1a, lane 5). Cleavage of TorA-MalE335 by TatAC-INV was a timedependent process (Fig. 1c) and was not a unique feature of this precursor, but was similarly obtained for the Tat model protein TorA-mCherry (Fig. 1d, lane 5) and TorA-PhoA (see below Fig. 2c).

Processing of the TorA-precursors by the TatB-deficient TatACvesicles required an intact RR-consensus motif (Fig. 2a). Replacement of the essential RR-residues of the TorA-MalE335 and TorA-mCherry fusion proteins by pairs of lysines resulted in the expected block of translocation and processing of both precursors by TatABC-containing membrane vesicles (Fig. 2a, compare lanes 3, 4 to 9, 10; Fig. 2b, lanes 5-8). Importantly, processing of the KK-mutant TorA-precursors by the TatACvesicles lacking TatB was also totally abolished (compare in Fig. 2a, lanes 5 and 11; in Fig. 2b, lanes 9 and 11) indicating that recognition of the authentic twin-arginine motif by the TatBdeficient TatAC-vesicles was a prerequisite for them to cleave unaltered TorA-precursors. This would not be the case, if processing of the precursor were due to unspecific proteases.

In order to test if processing of the TorA-precursors in the absence of TatB was in fact executed by signal peptidase, we made use of a mutant TorA-PhoA precursor, the signal peptide cleavage site of which had been inactivated by mutating its sequence from ATA-AQA to ATL-LQA ${ }^{27}$. This non-cleavable variant of TorA-PhoA was not processed by the TatAC-vesicles lacking TatB (Fig. 2c, lanes 5 and 11). Thus the findings depicted in Fig. 2 suggest 
a

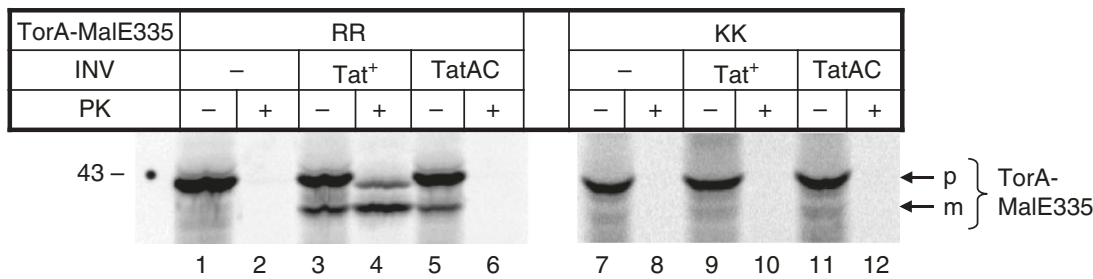

b

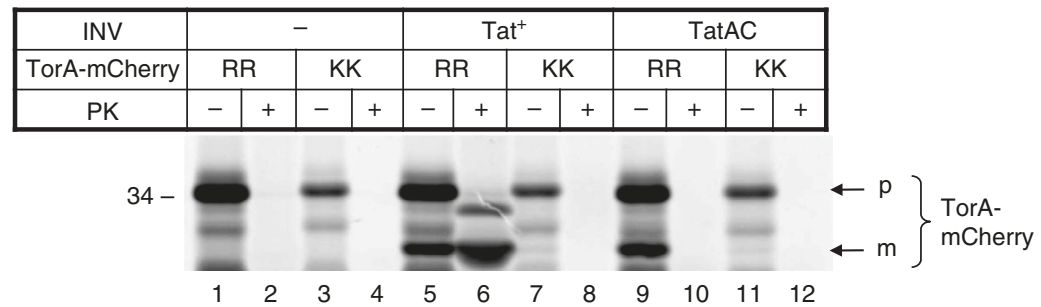

C

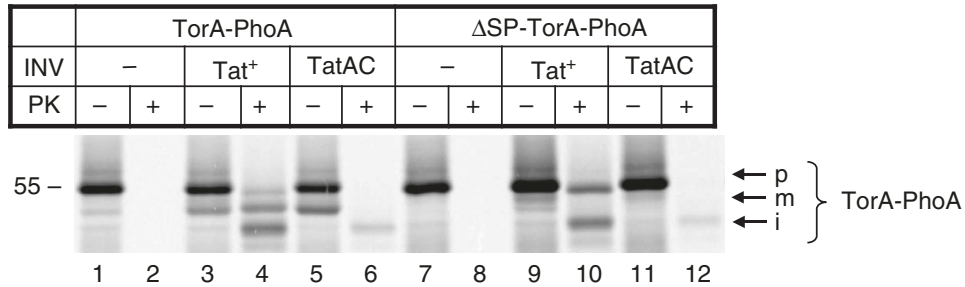

Figure 2 | RR-motif and cleavage site mutations abolish processing by TatB-deficient TatAC-vesicles. (a,b) In vitro synthesis of the radiolabelled TorAMalE335 and TorA-mCherry precursors in the absence and presence of INV containing TatABC $\left(\mathrm{Tat}^{+}\right.$) or TatAC. Transport and processing by Tat ${ }^{+}$-INV are completely abolished if the signal sequences of both precursors carry the KK-mutation. Similarly, cleavage of the TorA-precursors by the TatB-deficient TatAC-vesicles does not occur when the authentic RR-motif is mutated to KK. (c) As in $(\mathbf{a}, \mathbf{b})$ comparing the RR-precursor TorA-PhoA to its non-cleavable variant $\triangle \mathrm{SP}$-TorA-PhoA. As expected, the processed mature form of wild-type TorA-PhoA recovererd from Tat ${ }^{+}$-INV after PK-treatment ( $\mathrm{m}$ ) is not obtained for $\triangle \mathrm{SP}$-TorA-PhoA (compare lanes 4 and 10). Furthermore, no processed form of the $\triangle \mathrm{SP}$-TorA-PhoA precursor is detectable in TatB-deficient TatAC-vesicles (compare lanes 5 and 11), indicating that cleavage requires an intact signal peptidase cleavage site. The band labelled (i) is a translocation intermediate uniquely observed for TorA-PhoA ${ }^{27}$.

that despite lacking $\mathrm{TatB}$, TatAC-vesicles recognize the twinarginine motif of the TorA-signal peptide and mediate access of its cleavage site to signal peptidase.

TatB prevents premature signal peptide cleavage. Tat-specific transmembrane translocation requires the PMF at the membrane. Accordingly, the protonophore carbonyl cyanide m-chlorophenyl-hydrazone (CCCP) completely abolished translocation of TorA-MalE335 into TatABC-INV (Fig. 3a, compare lanes 6 and 8 ). Of note, no signal sequence cleavage by TatABC-INV was observed in the presence of CCCP (compare lanes 5 and 7), indicating that the wild-type Tat translocase allows processing of TorA-MalE335 only in conjunction with translocation. On the contrary, signal sequence cleavage obtained by the TatAC-vesicles in the absence of TatB was virtually unaffected by CCCP (compare lanes 9 and 11). Hence in this experimental setup, translocation of the twin-arginine signal peptide per se, as opposed to that of the complete precursor protein, proceeds without PMF.

Processing of the signal peptide, with the mature part of TorAMalE335 remaining untranslocated, invokes a hairpin-like insertion of the signal sequence and early mature part of TorAMalE335 into the membrane of TatAC-vesicles. Consistent with such a scenario, the signal sequence-less MalE-moiety when deprived of its membrane anchor by the processing activity of the TatAC-vesicles could largely be extracted by sodium carbonate (Fig. 3b, lanes 5 and 6). This was in contrast to the processed form of TorA-MalE335 obtained from TatABC- $\left(\right.$ Tat $\left.^{+}{ }_{-}\right)$INV (lanes 3 and 4), in which case translocation of the MalE-moiety rendered it for the most part carbonate-resistant. Moreover, these findings suggest that in the presence of an intact TatABC translocase, a futile cleavage of the twin-arginine signal peptide uncoupled from translocation of the passenger protein is prevented by the presence of TatB. This property seems to be unique for TatB as it was not shared by TatA being present in comparable amounts in TatAC- and TatABC-vesicles (Fig. 1b).

TatC mediates membrane insertion of an RR-signal sequence. Next we prepared INV from an E. coli strain that expressed TatC as the only Tat component (Fig. 1b, lane 3). Clearly these TatCINV allowed undiminished processing of TorA-mCherry and TorA-MalE335 when compared with TatAC-vesicles (Fig. 4a, compare lanes 5 and 7). That signal sequence cleavage by TatConly INV was in fact promoted by TatC, was demonstrated by a direct comparison between TatC-INV and those prepared from a total tat deletion strain. Although these $\Delta$ Tat vesicles gave rise to some degradation products of both precursors (and all others tested), none of these fragments comigrated with the signal sequence-less mature forms processed by the TatAC- and TatCINV (compare lanes 5 and 7 to 9). These results would be consistent with TatC functioning as an insertase of a twin-arginine signal peptide thereby mediating its exposure to signal peptidase (Fig. 4b, left). 
a

\begin{tabular}{|c|c|c|c|c|c|c|c|c|c|c|c|c|}
\hline INV & \multicolumn{4}{|c|}{-} & \multicolumn{4}{|c|}{ Tat $^{+}$} & \multicolumn{3}{|c|}{ TatAC } \\
\hline CCCP & \multicolumn{2}{|c|}{-} & \multicolumn{1}{|c|}{+} & \multicolumn{2}{|c|}{+} & \multicolumn{2}{|c|}{+} \\
\hline PK & - & + & - & + & - & + & - & + & - & + & - & + \\
\hline
\end{tabular}

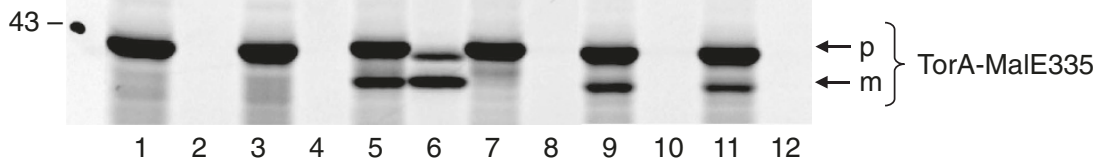

b

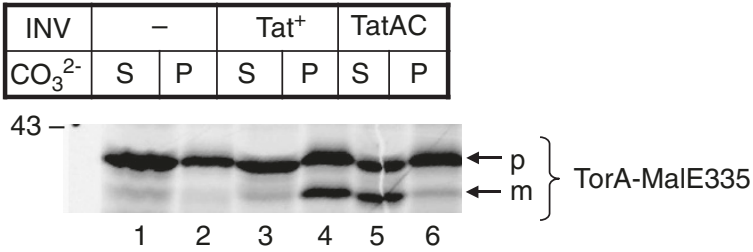

Figure 3 | TorA-signal sequence cleavage is independent of PMF in the absence of TatB. (a) TorA-MalE335 was synthesized in the absence or presence of the indicated vesicles, one part each containing the uncoupler CCCP at $0.1 \mathrm{mM}$, the other only the solvent dimethylsulphoxide. Whereas CCCP completely blocks translocation of TorA-MalE335 into Tat ${ }^{+}$-INV (lane 8) and thereby also prevents processing by the signal peptidase (lane 7), processing obtained by the TatB-lacking vesicles is unaffected by adding CCCP (lane 11). Thus, premature processing of TorA-MalE335 uncoupled from translocation of its MalE-moiety obviously results from a PMF-independent translocation of the TorA signal sequence cleavage site across the membrane. (b) After synthesis of TorA-MalE335 without or with the indicated INV, samples were treated with $0.2 \mathrm{M} \mathrm{Na}_{2} \mathrm{CO}_{3}$. Most of the processed form of TorA-MalE335 obtained from Tat ${ }^{+}$-INV is carbonate-resistant due to translocation into the vesicles and, therefore, sediments with the INV ( $P$, pellet). In contrast, TorA-MalE335 processed by TatAC-INV but not translocated because of a lack of TatB is released into the carbonate-soluble fraction (S, supernatant).

a

\begin{tabular}{|c|c|c|c|c|c|c|c|c|c|c|}
\hline INV & \multicolumn{2}{|c|}{-} & \multicolumn{2}{|c|}{ Tat $^{+}$} & \multicolumn{2}{|c|}{ TatAC } & \multicolumn{2}{|c|}{ TatC } & \multicolumn{2}{|c|}{$\Delta$ Tat } \\
\hline PK & - & + & - & + & - & + & - & + & - & + \\
\hline
\end{tabular}
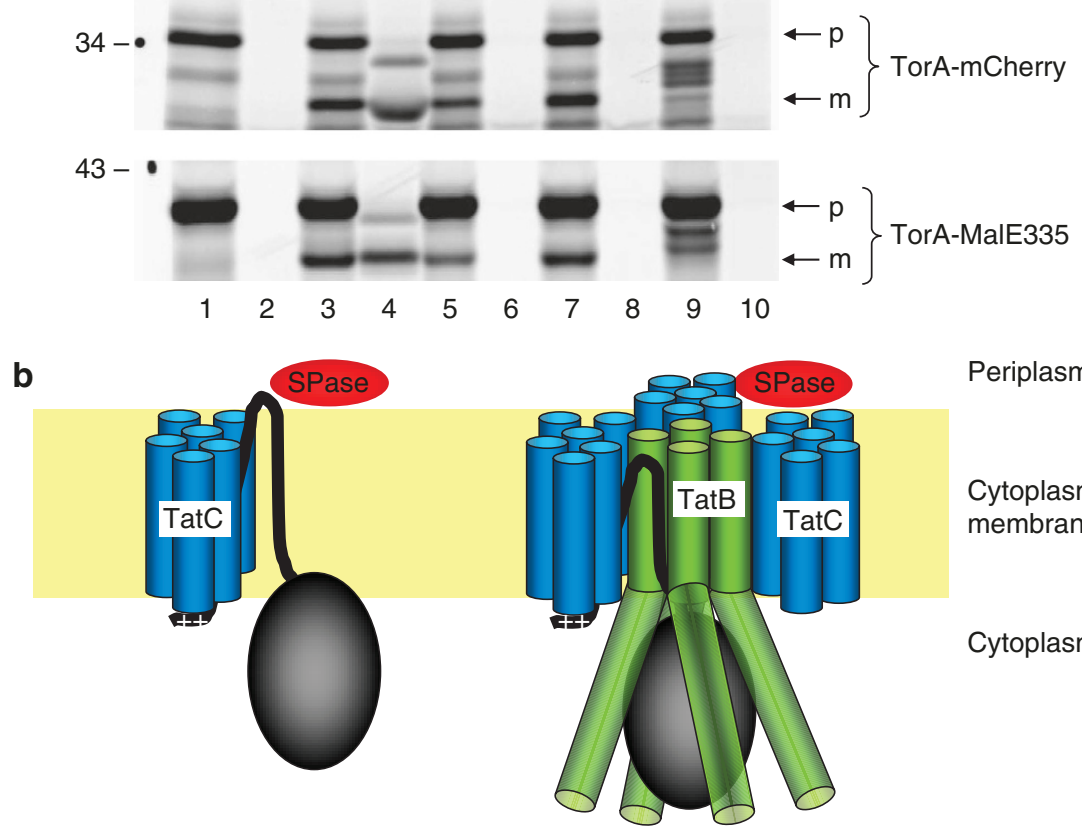

Periplasm

Cytoplasmic

membrane

Cytoplasm

Figure 4 | TatC alone can translocate TorA-precursor signal sequence cleavage sites. (a) TorA-mCherry and TorA-MalE335 were synthesized in the absence and presence of the indicated vesicles. TatC-INV were prepared from a $\Delta$ tat strain expressing only TatC, while $\Delta$ Tat-INV do not contain any Tat component. Vesicles containing only TatC allow the same processing of TorA-mCherry and TorA-MalE335 as TatAC-INV. As expected, correct signal sequence cleavage is, however, not observed for vesicles prepared from a total tat deletion strain. The reason for the partial instability of both precursors in the presence of $\Delta$ Tat-INV is not clear. (b) Model of possible TatC/TatB-signal sequence interactions. The yellow bar represents the lipid bilayer. The TatC molecule is depicted by six transmembrane helices (blue). Four TatB monomers are shown (green cylinders) following a recent report ${ }^{45}$. TatB and TatC form 1:1 complexes ${ }^{14}$. For clarity, the front TatC molecule has been omitted. The twin-arginine signal sequence $(++)$ is represented by a black line and the folded mature part of a RR-precursor by a black ellipse. TatC acts as an insertase of a twin-arginine signal peptide thereby mediating its exposure to signal peptidase (SPase). Embedding the signal sequence in a TatBC-binding pocket interferes with a premature cleavage by signal peptidase. 
Structural requirements for premature cleavage. The situation depicted in Fig. 4b (left) requires that both the signal sequence preceding the cleavage site and the early mature region of the precursor allow the loop to extend onto signal peptidase. To prove this, we also employed the two natural E. coli Tat substrates Sufl (FtsP) and AmiC. As shown in Fig. 5a, although both in vitro synthesized precursors were translocated into and concomitantly cleaved by TatABC-INV (lanes 3 and 4), no proteolytic processing was obtained by TatAC-INV lacking TatB (lane 5), which is in clear contrast to the TorA-precursors described above. This result definitely rules out the possibility that cleavage of the TorAprecursors by the TatAC-INV was due to any contamination by right-side out vesicles exposing signal peptidase on their outside. Assuming that the lack of processing of pSufI and pAmiC by TatAC-vesicles originated from the nature of the signal peptides of these two RR-precursors, we replaced the authentic signal sequence of SufI by that of TorA, creating a TorA-SufI fusion protein. Figure $5 \mathrm{~b}$ illustrates that this TorA-SufI model protein was as efficiently processed by, and translocated into functional TatABC-INV as wild-type pSufI (compare lanes 3, 4 and 9, 10). However, only TorA-SufI was processed by TatAC-vesicles (compare lanes 5 and 11). Hence, TatC-mediated transport and processing observed in the absence of TatB became manifest only for the TorA-signal peptide.

Figure $5 \mathrm{c}$ compares the signal sequence of TorA with those of Sufl and AmiC. Evidently they differ in length, in particular in the distance between the consensus motif (in bold letters) and the cleavage site (underlined). In addition, all TorA-fusions so far used contain a linker sequence engineered between the TorAsignal sequence and the respective passenger protein. It was, therefore, conceivable that in the case of the TorA-signal peptide, both the comparably long hydrophobic sequence upstream of the cleavage site and the downstream linker sequence would facilitate exposure to signal peptidase.

We, therefore, removed the linker from the TorA-Sufl fusion. The resulting construct (Fig. $5 c$, TorA-SufI $\Delta$ Linker) was efficiently cleaved by, and translocated into, $\mathrm{Tat}^{+}$-INV (Fig. 5d, lanes 3,4$)$ but was only poorly processed by the TatB-lacking vesicles (compare lanes 3 and 5) suggesting that the presence of the linker sequence in fact facilitates access to signal peptidase.

In order to separately examine the influence of the distance between the RR-consensus motif and the cleavage site of signal peptides on the processing by the TatB-lacking vesicles, we also extended the signal sequence of Sufl by duplicating the amino acid stretch AGAVPL thus generating the longer precursor SufIss-ex (Fig. 5c). Exactly as anticipated, this extension now rendered the signal sequence of Sufl a much better substrate of the signal peptidase in the absence of TatB (compare Fig. 5d, lane 11 with Fig. 5b, lane 5).

In addition, we also tested the natural Tat substrate NapG for processing by TatB-deficient vesicles. The signal sequence of NapG exhibits about the same overall length and distance between consensus motif and cleavage site as that of TorA (Fig. 5c). NapG is a FeS-containing periplasmic protein ${ }^{44}$. Owing to the incapability of our cell-free system to incorporate FeSclusters, the in vitro synthesized NapG was neither processed nor translocated by Tat ${ }^{+}$-INV (Fig. 5e, compare lanes 1,2 with 3,4 ). However, despite being a translocation-incompetent RRprecursor, a cleavage product of pNapG was formed by the TatB-lacking TatAC- and TatC-only vesicles (lanes 5 and 7, mNapG), that by size corresponds to the $20.5 \mathrm{kDa}$ signal sequence-less form of NapG.

Finally, we investigated if TatC could also in vivo be shown to mediate access of RR-precursors to the signal peptidase. For this purpose, we compared wild-type E. coli BL21(DE3) cells expressing TatC together with TatAB from the chromosomal tat operon (Fig. 6a, TatABC-cells, lane 3) with an isogenic $\Delta$ Tat derivative (lane 4 ) and with the $\Delta$ Tat mutant uniquely expressing TatC from an arabinose-inducible plasmid-borne tatC gene (TatC-cells, lanes 1 and 2). These three strains were each transformed with plasmids encoding one of the RR-precursors pSufl, pNapG or TorA-mCherry. Cells were grown in minimal media, induced for the synthesis of the respective RR-precursor and labelled with ${ }^{35}[\mathrm{~S}]$-methionine/cysteine. As expected, the precursor of SufI was found processed by TatABC-cells suggesting its export to the periplasm, but remained uncleaved in $\triangle$ Tat-cells, because the lack of TatABC prevented any Tatspecific translocation (Fig. 6b, upper panel, lanes 1, 2). In agreement with the results obtained in vitro (Fig. 5a), cells expressing only $\mathrm{TatC}$ did not allow cleavage of the signal sequence of pSufI (Fig. 6b, upper panel, lane 3).

In striking contrast, the same cells, which of note differ from the isogenic $\Delta$ Tat-cells only by the isolated expression of TatC, allowed processing of the NapG precursor to a product of the size of mature NapG (Fig. 6b, middle panel, lane 3). We were, however, unable to recover the same species of NapG from the TatABC-expressing cells that show processing of SufI (Fig. 6b, lane 1). A possible explanation for this failure is that any processed, that is, translocated NapG in TatABC-containing cells is unstable when expressed in the absence of the membrane protein $\mathrm{NapH}$, to which NapG is proposed to bind after transport into the periplasm ${ }^{44}$. Consistent with this assumption, premature cleavage of the NapG precursor by cells expressing solely TatC (Fig. 6b, middle panel, lane 3) leads to a stable form of mature NapG protected against degradation by periplasmic proteases, because in the absence of Tat A and TatB-signal sequence cleavage is uncoupled from export to the periplasm. In other words, recovery of processed NapG from cells expressing only TatC can be taken as a clue that even in vivo TatC translocates the cleavage site of appropriately sized RR-signal peptides, such as that of NapG, across the membrane. To further confirm this notion, we performed pulse-labelling also with cells expressing TorAmCherry (Fig. 6b, lower panel). Like pSufI, TorA-mCherry was again found processed by TatABC-cells (lane 1). Notably, the same cleavage product was formed in TatC-only cells (lane 3) again suggesting that the $\mathrm{TatC}$-mediated premature cleavage of the TorA-signal peptide from this RR-precursor also occurred in vivo.

In summary, our results strongly suggest that TatC is able to insert and position Tat signal sequences in a transmembrane orientation (Fig. 4b). Provided that the sequence context upstream and downstream of the cleavage site allows for sufficient conformational flexibility this could even lead to premature cleavage by signal peptidase, which under physiological conditions would, however, be counteracted by TatB.

\section{Discussion}

The experiments described here suggest that TatC, which thus far has mainly been characterized as part of a Tat-specific signal sequence receptor, additionally seems to function in the generation of the transmembrane orientation of RR-signal sequences. This signal peptide-insertase activity of TatC neither requires TatB nor TatA. As depicted in the model of Fig. $4 \mathrm{~b}$, TatC would thus drive a hairpin-like embedment of RR-precursor proteins in the target membrane. Under normal conditions, that is in the presence of TatB, the TatC-mediated insertion would lead to the accommodation of the Tat signal sequence in a binding pocket jointly formed by $\mathrm{TatC}$ and TatB. As previous studies have revealed an oligomeric assembly of $\mathrm{TatB}^{21}$ in particular when interacting with RR-precursors ${ }^{45}$, we depicted in the model of Fig. $4 \mathrm{~b}$ TatB as the tetrameric complex previously 
a

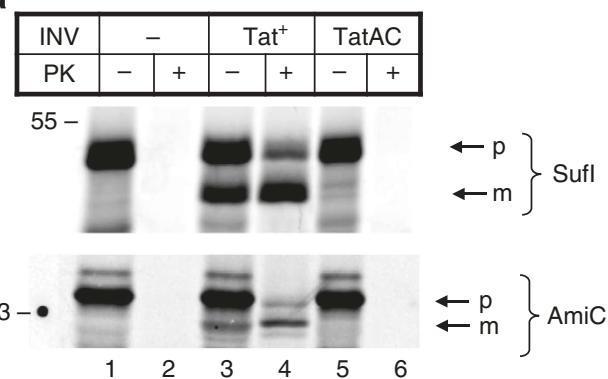

b

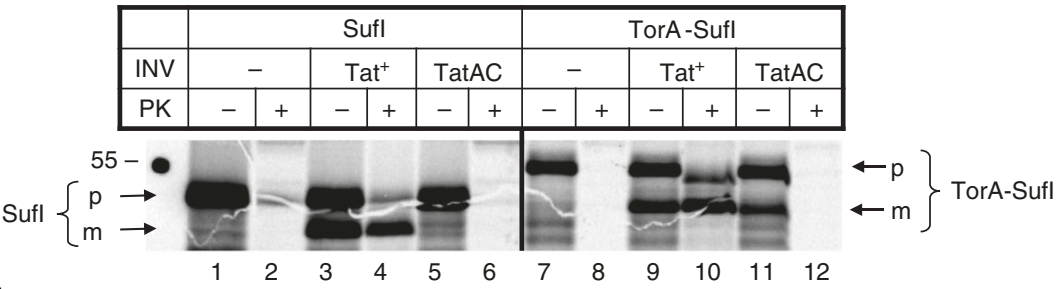

C

MSLSRRQFIQASGIALCAGAVPLKASAAGQ

MSLSRRQFIQASGIALCAGAVPLAGAVPLKASAAGQ

MSGSNTAISRRRLLQGAGAMWLLSVSQVSLAAVS

MNNNDLFQASRRRFLAQLGGLTVAGMLGPSLLTPRRATAAQAATDAVef

MNNNDLFQASRRRFLAQLGGLTVAGMLGPSLLTPRRASAAGQ

MSRSAKPQNGRRRFLRDVVRTAGGLAAVGVALGLQQQTARASGV
Sufl

Sufl-ss-ex

AmiC

TorA

TorA-Sufl $\Delta$ Linker

NapG

d

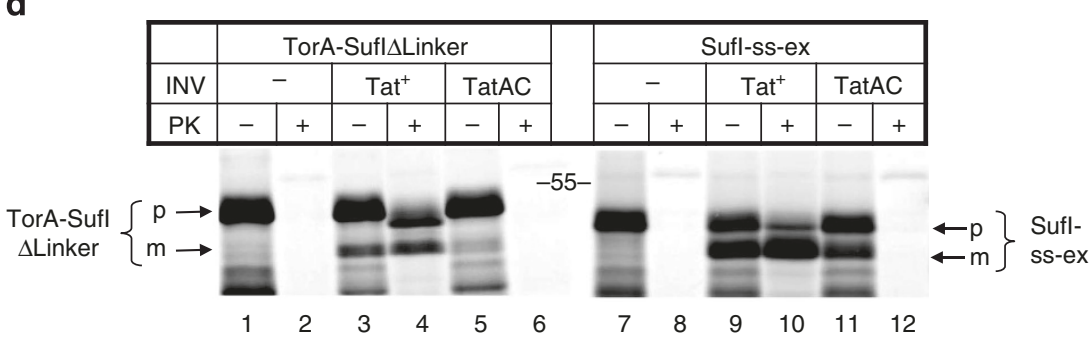

e

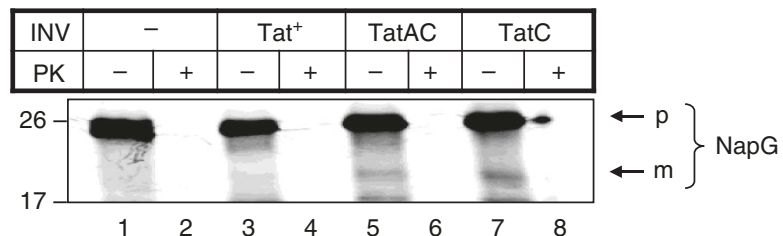

Figure 5 | Premature processing in the absence of TatB depends on structural determinants of RR-precursors. (a) Sufl and AmiC were synthesized in

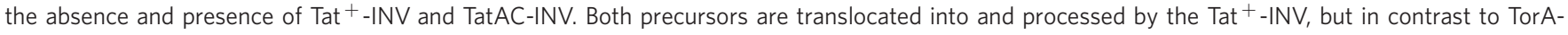
precursors, are not processed by TatAC-INV lacking TatB. (b) To create the TorA-Sufl fusion protein, the authentic signal sequence of Sufl was replaced by that of TorA. TorA-Sufl is as efficiently processed by and translocated into functional TatABC-INV as is pSufl. However, only TorA-Sufl is processed by TatAC-INV lacking TatB. (c) Comparison of the different Tat signal sequences used. The consensus motifs are printed in bold letters and the six amino flanking each cleavage site are underlined. Residues of the early mature regions of each precursor are given in italic letters. The TorA signal sequence was fused to the various passenger proteins via a 10 amino acid long linker that consists of eight residues derived from mature TorA (italic capital letters) and two amino acids encoded by nucleotides that had been introduced for cloning reasons (italic lower case letters). In TorA-Sufl $\Delta$ Linker, this linker region was removed now connecting the first residues of Sufl (AGQ) directly to the TorA signal sequence. To obtain more efficient processing, the C-terminal ATAresidues of the TorA signal peptide were changed to the Sufl-derived ASA-motif. (d) To define the features that render the TorA signal sequence cleavable in the presence of TatC, the linker downstream of the cleavage site was removed from the TorA-Sufl construct (TorA-Sufl $\Delta$ Linker) and the signal sequence of Sufl was extended by six amino acids (Sufl-ss-ex, cf. (c)). Compared with TorA-Sufl, TorA-Sufl $\Delta$ Linker is less efficiently processed by the TatB-lacking TatAC- and TatC-INV, whereas compared with Sufl, Sufl-ss-ex acquired the capability of being processed. (e) NapG is an E. coli RR-precursor whose FeScofactor is not incorporated by our in vitro system. In vitro synthesized NapG, therefore, is neither processed nor translocated by Tat ${ }^{+}$-INV. Despite being translocation-incompetent, the NapG precursor is processed by the TatB-lacking TatAC- and TatC-INV yielding a cleavage product of the size of the signal sequence-less mature NapG. 
a

\begin{tabular}{|c|c|c|c|c|}
\hline Antibody & \multicolumn{4}{|c|}{$\alpha$ TatC } \\
\hline Cells & \multicolumn{2}{|c|}{ TatC } & TatABC & $\Delta$ Tat \\
\hline $0.1 \%$ Arab. & - & + & \multicolumn{2}{|c|}{-} \\
\hline $26-$ & & & & \\
& 1 & 2 & 3 & 4
\end{tabular} TatC

b
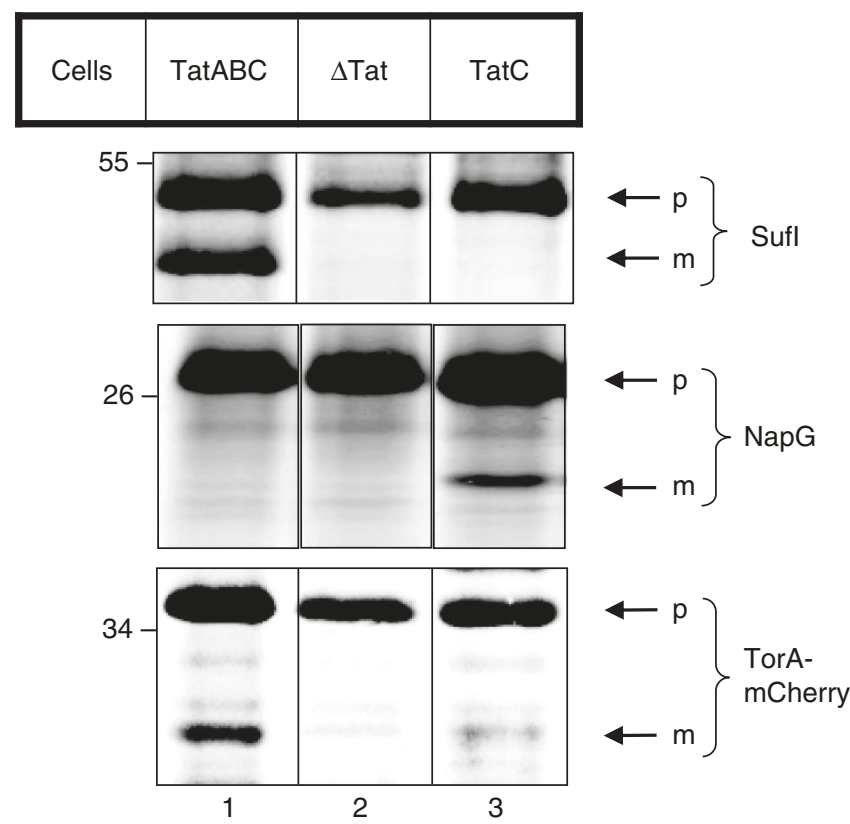

Figure 6 | TatC-mediated cleavage of RR-signal peptides is also observed in vivo. (a) E. coli BL21(DE3) cells used for pulse/chase labelling of RRprecursors either expressed TatC from the araBAD promoter in the absence of Tat $A$ and TatB (TatC-cells), or TatABC from the chromosomal tat operon (TatABC-cells), or were devoid of all Tat subunit ( $\triangle$ Tat-cells). Equivalent amounts of cells were blotted against anti-TatC antibodies ( $\alpha$ TatC).

(b) Cells of the indicated strains were pulse/chase-labelled as detailed in the Methods section and labelled Sufl, NapG and TorA-mCherry species were purified via Ni-affinity chromatography. Note the processing of the NapG and TorA-mCherry precursors when cells expressed solely TatC.

proposed following a cysteine crosslinking analysis ${ }^{46}$. The model further suggests that fixation of the Tat signal sequence between TatC and TatB helps to prevent an exposure of the signal sequence cleavage site to signal peptidase before translocation of the mature part of the precursor protein. This idea is derived from the findings described here that a Tat translocase lacking TatB can allow processing of a translocation-incompetent RRprecursor (Fig. 5e, lanes 5, 7) and the premature removal of the signal sequence even from an otherwise translocation-proficient Tat substrate (Fig. 3a, lane 11).

A hairpin-like insertion of RR-precursors into TatBC would be a corollary of the N-proximal part of a Tat signal peptide being captured at the cytosolic side of the membrane. Such a precursor topology is consistent both with a superficially exposed precursor binding site provided by $\mathrm{TatC}^{29}$ and the protease accessibility demonstrated for RR-precursors bound to the thylakoidal Tat translocase ${ }^{47,48}$. Similarly all TorA-fusions analysed in here were found to become slightly shortened by PK added after their translocation into Tat $^{+}$-vesicles (Fig. 1a, lane 4; Fig. 1d, lane 4; Fig. 2c, lane 10; Fig. 5b, lane 10). This phenomenon became manifest because membrane vesicles as used here usually fail to process all translocated precursor molecules by their resident signal peptidase. As uncleaved precursor molecules remain membrane-anchored they consequently constitute a target for externally added proteases.

The presumed insertase activity of TatC would position the signal sequence and, depending on the depth of insertion, some amino acids of the early mature region of an RR-precursor into a membrane-embedded binding pocket, which the model of Fig. $4 \mathrm{~b}$ suggests to be formed by TatC and TatB. A deep loop-like insertion of an RR-precursor between $\mathrm{TatB}$ and $\mathrm{TatC}$ is experimentally supported by (1) suppressor mutations located near the trans-sided N-terminus of TatB that compensate the translocation defect of mutant TorA-precursors ${ }^{25,26}$; (2) crosslinking of the same area of TatB to the precursors of TorA and Sufl ${ }^{45}$; (3) preferential crosslinking of the hydrophobic part of Tat signal peptides located downstream of the RR-consensus motif to $\mathrm{TatB}^{23,24,27}$; (4) site-specific crosslinking between transmembrane helices of TatC and $\mathrm{TatB}^{49}$.

If TatC catalyses the transmembrane insertion of Tat signal peptides it would function in a similar way as the YidC protein insertase present in bacterial cytoplasmic membranes, which is involved in the insertion process of $\alpha$-helical membrane proteins ${ }^{50}$. Similar to TatC, members of the YidC/Oxa1/Alb3 family, which are also found in mitochondria and chloroplasts, harbour five to six predicted transmembrane domains and are believed to form a platform for the insertion of the hydrophobic transmembrane helices of their substrates. Whereas YidC clients in general are released into the lipid bilayer after they adopted their transmembrane orientation, RR-signal peptides seem to remain attached to TatC even after translocation of the entire mature domain ${ }^{24}$.

In summary, the model shown in Fig. $4 \mathrm{~b}$ proposes that after recognition of the $\mathrm{RR}$ - consensus motif by TatC at the cytosolic surface of the Tat translocase, the proposed insertase activity of TatC inserts and accommodates the signal peptide in a concerted TatBC-binding groove, a process that most likely also involves reorientation events that might depend on the function of TatB and the presence of the PMF ${ }^{47,51}$. Recent data obtained with the E. coli Tat machinery suggest that monomeric TatA might be recruited at this early stage in a PMF-sensitive manner ${ }^{52}$. Before the start of translocation a single precursor molecule has been found in contact with more than one TatB molecule ${ }^{45}$. Whether this stage simply reflects the interaction of an RR-precursor with preformed oligomeric TatBC structures ${ }^{21,22,53}$ or results from a precursor-mediated oligomerization of TatBC units is not known. An oligomeric TatB structure formed around a TatC-anchored precursor could then serve as the nucleation point for the recruitment of numerous TatA protomers and even the formation of higher-order oligomeric TatABC complexes eventually allowing the transmembrane passage of the precursor. Assembly of TatA on a TatB-based scaffold would allow a lateral access of the substrate to the protein-conducting structure rather than having to invoke a transfer event between a receptor complex and a pore structure. During all these assembly steps the RR-precursor would remain fixed via its signal sequence to its initial TatCbinding site. It is even conceivable that such a stable association of the Tat signal peptide with $\mathrm{TatC}$ is a prerequisite for forming and maintaining the Tat-specific protein conduit in the membrane. Completion of translocation, which in fact can proceed without removal of the signal sequence 24,54 , would then lead to cleavage of the RR-precursor by signal peptidase and a subsequent dissociation of the signal peptide from TatBC would be the trigger for the dissociation of the Tat translocase. 


\section{Methods}

Plasmids. Plasmids were all verified by DNA sequencing. Plasmid pPJ7 (pET22b + /NapG) was constructed by PCR using total DNA of E. coli Top10 cells as template and the primers 5-NapG NdeI and 3-NapG XhoI (Supplementary Table S1). PCR was performed with Quick-Load Taq 2x Master-Mix (New England Biolabs). The PCR product was digested with NdeI/XhoI and ligated into pET22b + cut with the same restriction enzymes.

Plasmid pPJ8 (pKSM/SufI-ss-ex) was generated by inverse PCR as described for plasmid pPJ6 (ref. 29) using the primers SufI ss ex. for and SufI ss ex. rev and pKSMSufI-RR ${ }^{23}$ as template.

To construct plasmid pPJ9 (pASK-IBA33plus/SufI), the Suff-encoding DNA sequence was amplified via PCR using Pfu Polymerase (Fermentas), pKSMSuff-RR ${ }^{23}$ as template and the primers Sufl IBA3 for and Sufl IBA3 rev. The PCR fragment and the recipient vector pASK-IBA33plus were digested with $B s a \mathrm{I}$ and ligated.

To construct plasmid pPJ10 (pBAD33/TatC), the TatC-encoding DNA sequence was amplified via PCR using Pfu Polymerase, plasmid p 8737 as template ${ }^{55}$ and the primers $5^{\prime}$-SacI TatC and $3^{\prime}$-BglII TatC. The PCR fragment and the recipient vector $\mathrm{pBAD} 33$ were digested with SacI and BglII and ligated following dephosphorylation of the vector by antarctic phosphatase (New England Biolabs). To add a Shine-Dalgarno sequence upstream of TatC, the resulting plasmid was linearized with SacI, followed again by dephosporylation. It was then incubated for $5 \mathrm{~min}$ at room temperature with the phosporylated oligos P-SacI pBAD for and P-SacI pBAD rev that encode the Shine-Dalgarno sequence present in pET22b + and finally re-ligated. Owing to the cloning strategy, two additional amino acids were added to the C-terminus of TatC.

Plasmid $\mathrm{p} 8737$-tat $A C$ was constructed to generate a tat $A C$ expression vector with a tatA upstream region that is similar to the tat $A B C D$ expression vector p8737 using a 'crossover'-PCR method. First the tatA upstream region from p8737 was amplified by using the forward primer LacI_int_vorne_for and the reverse Primer Co_p8737_AC_rev with p8737 serving as template. Next, the tatAC operon was amplified by using the forward primer Co_AC_p8737_for, which has a $5^{\prime}$-extension that is complementary to the $3^{\prime}$-end of the first PCR product, and the reverse primer TatC_Ende_NdeI_rev with pHSG-TatAC ${ }^{40}$ as template. Both fragments were purified and used as a template in a crossover PCR using primers LacI_int_vorne_for and TatC_Ende_NdeI_rev. The obtained PCR fragment was digested with XbaI and NdeI and ligated into the $\mathrm{XbaI} / \mathrm{NdeI}$ digested p8737 plasmid backbone, resulting in plasmid p8737-tatAC. All PCR reactions were carried out using the Expand High Fidelity PCR system (Roche).

Plasmids pKSMSuff-RR encoding Suff ${ }^{23}$, pET28aTorA-PhoA and pET28aTorAPhoA $\triangle$ SP encoding TorA-PhoA and a non-cleavable variant of it ${ }^{27}$, pPJ1 encoding TorA-MalE335 lacking the $35 \mathrm{C}$-terminal residues of $\mathrm{MalE}^{52}$, pPJ2 encoding TorA(KK)-MalE335 (ref. 29), pPJ3 encoding TorA-mCherry ${ }^{52}$, pPJ4 encoding Suff ${ }^{29}$, pPJ5 encoding TorA(KK)-mCherry ${ }^{52}$, pPJ6 (ref. 29) encoding TorA-SufI $\Delta$ Linker, which is a linker-less version of TorA-Sufl encoded by pPJ4, pTF1 encoding AmiC ${ }^{29}$, p8737 containing an T7-dependent tatABCD operon ${ }^{55}$, and pFAT588 encoding a hexa-histidine-tagged version of $\mathrm{TatC}^{56}$ have been described previously.

In vitro reactions. S-135 cell extracts were obtained from E. coli strains SL119 (ref 57) and Top10 (Invitrogen). Cells were grown and S-135 cell extracts were prepared as described ${ }^{43}$

Coupled transcription/translation of the different precursor proteins from plasmid DNAs was performed as described ${ }^{43}$. Tat-dependent translocation of TorA-PhoA requires oxidizing condition $\mathrm{s}^{27}$. Those were established by the addition of $5 \mathrm{mM}$ oxidized glutathione (GSSG) at the start of synthesis.

Membrane vesicles were added $10 \mathrm{~min}$ after starting the synthesis reaction and incubated for $25 \mathrm{~min}$ at $37^{\circ} \mathrm{C}$. For assaying translocation of precursors into INV, $15 \mu \mathrm{l}$ of each reaction were treated with $15 \mu \mathrm{l} 10 \%$ (w/v) trichloroacetic acid (TCA) and $30 \mu \mathrm{l}$ were incubated with PK according to Moser et al. ${ }^{43}$ Where appropriate, CCCP was added at $0.1 \mathrm{mM}$ final concentration together with INV.

For sodium carbonate extraction, a $50 \mu \mathrm{l}$ reaction was treated with $50 \mu \mathrm{l}$ freshly prepared, ice- cold $0.4 \mathrm{M} \mathrm{Na}_{2} \mathrm{CO}_{3}$. After $30 \mathrm{~min}$ at $4{ }^{\circ} \mathrm{C}$, samples were centrifuged for $30 \mathrm{~min}$ at 70,000 r.p.m. in a Beckman TLA100 ultracentrifuge (BeckmanCoulter) using a TLA 100.3 rotor. Afterwards supernatants were precipitated with $100 \mu \mathrm{l} 10 \%(\mathrm{w} / \mathrm{v})$ TCA and resuspended in SDS-PAGE loading buffer. The pellets were solubilized directly in $30 \mu \mathrm{l}$ SDS-PAGE loading buffer.

Preparation of membrane vesicles. INV were prepared as described previously $y^{43}$ from E. coli strain BL21(DE3) $\Delta$ Tat (B. Ize and T. Palmer, personal communication) transformed with plasmid p8737 (Tat ${ }^{+}$-INV), p8737-tatAC (TatAC-INV) and pFAT588 (TatC-INV). Expression of tat genes was induced with $1 \mathrm{mM}$ isopropyl $\beta$-D-thiogalactopyranoside during the growth of cells from an optical density (OD) at $600 \mathrm{~nm}$ of 0.5 up to 2.0 .

In vivo labelling of Tat precursors. Strains BL21(DE3), BL21(DE3) $\Delta$ Tat (see above) and BL21(DE3) $\Delta$ Tat containing plasmid pPJ10 (TatC) were transformed with plasmids pPJ9, pPJ3 and pPJ7 each. M63 minimal media supplemented with $10 \mathrm{mgl}^{-1}$ thiamine hydrochloride, $100 \mu \mathrm{M}$ each of 18 amino acids except methionine and cysteine, and the appropriate antibiotics were inoculated with overnight cultures of the respective strains to give an OD at $600 \mathrm{~nm}$ of 0.1 . After growth at $37^{\circ} \mathrm{C}$ to an $\mathrm{OD}_{600}$ of $0.25-0.3$, cells-harbouring plasmid pPJ10 (TatC) were induced with $0.1 \%$ arabinose. At an $\mathrm{OD}_{600}$ of $0.5-0.6,250 \mu \mathrm{l}$ of cell cultures expressing pSufl, and $500 \mu \mathrm{l}$ of cell cultures expressing TorA-mCherry and pNapG were each transferred to microfuge tubes and placed in an Eppendorf Thermomixer set at $37^{\circ} \mathrm{C}$. Cells were pulsed with $4 \mu \mathrm{ml}^{-1} 35[\mathrm{~S}]$-methionine/cysteine (11-15 $\mu \mathrm{Ci} / \mu \mathrm{l})$ and simultaneously treated with either $200 \mathrm{ng} \mathrm{ml}^{-1}$ anhydrotetracycline dissolved in dimethylsulphoxide to induce synthesis of pSufI from pPJ9 or with at least $1 \mathrm{mM} \beta$-D-thiogalactopyranoside to induce synthesis of TorAmCherry from plasmid pPJ3 and pNapG from plasmid pPJ7, respectively. After $5 \mathrm{~min}$ of pulse time in the case of pSuff and after $15 \mathrm{~min}$ in the case of TorAmCherry and $\mathrm{pNapG}$, cells were chased with non-labelled methionine and cysteine $\left(500 \mu \mathrm{g} \mathrm{ml}^{-1}\right.$ final concentration) for $60 \mathrm{~min}$. Reactions were stopped by the addition of 5\% TCA (final concentration) and incubation on ice for $30 \mathrm{~min}$. TCA precipitates were collected, dissolved in dithiothreitol-free SDS-PAGE loading buffer, treated with $8 \mathrm{M}$ urea and applied to Ni-Sepharose as described ${ }^{58}$ in order to isolate His-tagged SufI, TorA-mCherry and NapG species.

Miscellaneous. For western blotting, $4 \mu \mathrm{INV}\left(\mathrm{A}_{280} \sim 40 \mu \mathrm{ml}^{-1}\right)$ were each dissolved in $96 \mu$ l SDS-PAGE loading buffer. Of this solution, $5 \mu \mathrm{l}$ were used for SDS-PAGE and western transfer, when blots were decorated with anti-TatA antibodies, and $20 \mu \mathrm{l}$ when using anti-TatB and anti-TatC antibodies. Polyclonal antibodies against TatA, TatB and TatC were raised in rabbits as described ${ }^{23,55}$. The second antibody was goat anti-rabbit IgG coupled to alkaline phosphatase (Sigma). Detection was performed using NBT/BCIP Stock Solution (Roche) following the manufacturer's instructions. SDS-electrophoresis using $10 \%$ polyacrylamide gels was performed as described previously ${ }^{43}$.

\section{References}

1. Fröbel, J., Rose, P. \& Müller, M. Twin-arginine-dependent translocation of folded proteins. Philos. Trans. R. Soc. Lond. B. Biol. Sci. 367, 1029-1046 (2012)

2. Cline, K. \& Theg, S. M. The Sec and Tat protein translocation pathways, in chloroplasts. In Dalbey, R. E., Koehler, C. M. \& Tamanoi, F. (eds) Molecular Machines Involved in Protein Transport across Cellular Membranes, pp 463-492 (Elsevier, 2007)

3. Palmer, T. \& Berks, B. C. The twin-arginine translocation (Tat) protein export pathway. Nat. Rev. Microbiol. 10, 483-496 (2012).

4. Robinson, C. et al. Transport and proofreading of proteins by the twin-arginine translocation (Tat) system in bacteria. Biochim. Biophys. Acta 1808, 876-884 (2011).

5. Hou, B. \& Brüser, T. The Tat-dependent protein translocation pathway. BioMol. Concepts 2, 507-523 (2011).

6. Walther, T. H., Grage, S. L., Roth, N. \& Ulrich, A. S. Membrane alignment of the pore-forming component $\operatorname{Tat} \mathrm{A}(\mathrm{d})$ of the twin-arginine translocase from Bacillus subtilis resolved by solid-state NMR spectroscopy. J. Am. Chem. Soc. 132, 15945-15956 (2010)

7. Hu, Y., Zhao, E., Li, H., Xia, B. \& Jin, C. Solution NMR structure of the TatA component of the twin-arginine protein transport system from gram-positive bacterium Bacillus subtilis. J. Am. Chem. Soc. 132, 15942-15944 (2010).

8. Porcelli, I. et al. Characterization and membrane assembly of the TatA component of the Escherichia coli twin-arginine protein transport system. Biochemistry 41, 13690-13697 (2002).

9. Chan, C. S., Zlomislic, M. R., Tieleman, D. P. \& Turner, R. J. The TatA subunit of Escherichia coli twin-arginine translocase has an $\mathrm{N}$-in topology. Biochemistry 46, 7396-7404 (2007).

10. Gouffi, K., Gerard, F., Santini, C. L. \& Wu, L. F. Dual topology of the Escherichia coli TatA protein. J. Biol. Chem. 279, 11608-11615 (2004).

11. Koch, S., Fritsch, M. J., Buchanan, G. \& Palmer, T. Escherichia coli TatA and TatB proteins have N-out, C-in topology in intact cells. J. Biol. Chem. 287, 14420-14431 (2012).

12. Aldridge, C., Storm, A., Cline, K. \& Dabney-Smith, C. The chloroplast twin arginine transport (tat) component, tha4, undergoes conformational changes leading to tat protein transport. J. Biol. Chem. 287, 34752-34763 (2012).

13. Jakob, M., Kaiser, S., Gutensohn, M., Hanner, P. \& Klösgen, R. B. Tat subunit stoichiometry in Arabidopsis thaliana challenges the proposed function of TatA as the translocation pore. Biochim. Biophys. Acta 1793, 388-394 (2009).

14. Bolhuis, A., Mathers, J. E., Thomas, J. D., Barrett, C. M. \& Robinson, C. TatB and $\mathrm{TatC}$ form a functional and structural unit of the twin-arginine translocase from Escherichia coli. J. Biol. Chem. 276, 20213-20219 (2001).

15. McDevitt, C. A., Hicks, M. G., Palmer, T. \& Berks, B. C. Characterisation of Tat protein transport complexes carrying inactivating mutations. Biochem. Biophys. Res. Commun. 329, 693-698 (2005).

16. McDevitt, C. A., Buchanan, G., Sargent, F., Palmer, T. \& Berks, B. C. Subunit composition and in vivo substrate-binding characteristics of Escherichia coli Tat protein complexes expressed at native levels. FEBS J 273, 5656-5668 (2006).

17. Sargent, F. et al. Purified components of the Escherichia coli Tat protein transport system form a double-layered ring structure. Eur. J. Biochem. 268, 3361-3367 (2001). 
18. Oates, J. et al. Consensus structural features of purified bacterial TatABC complexes. J. Mol. Biol. 330, 277-286 (2003).

19. Cline, K. \& Mori, H. Thylakoid DeltapH-dependent precursor proteins bind to a cpTatC-Hcf106 complex before Tha4-dependent transport. J. Cell Biol. 154, 719-729 (2001).

20. Richter, S. \& Brüser, T. Targeting of unfolded PhoA to the TAT translocon of Escherichia coli. J. Biol. Chem. 280, 42723-42730 (2005).

21. Tarry, M. J. et al. Structural analysis of substrate binding by the TatBC component of the twin-arginine protein transport system. Proc. Natl Acad. Sci. USA 106, 13284-13289 (2009).

22. Ma, X. \& Cline, K. Multiple precursor proteins bind individual Tat receptor complexes and are collectively transported. EMBO J. 29, 1477-1488 (2010).

23. Alami, M. et al. Differential interactions between a twin-arginine signal peptide and its translocase in Escherichia coli. Mol. Cell 12, 937-946 (2003).

24. Gerard, F. \& Cline, K. Efficient twin arginine translocation (Tat) Pathway transport of a precursor protein covalently anchored to its initial cpTatC Binding site. J. Biol. Chem. 281, 6130-6135 (2006).

25. Kreutzenbeck, P. et al. Escherichia coli twin arginine (Tat) mutant translocases possessing relaxed signal peptide recognition specificities. J. Biol. Chem. 282, 7903-7911 (2007)

26. Lausberg, F. et al. Genetic evidence for a tight cooperation of TatB and TatC during productive recognition of twin-arginine (Tat) signal peptides in Escherichia coli. PLoS One 7, e39867 (2012).

27. Panahandeh, S., Maurer, C., Moser, M., DeLisa, M. P. \& Müller, M. Following the path of a twin-arginine precursor along the TatABC translocase of Escherichia coli. J. Biol. Chem. 283, 33267-33275 (2008).

28. Marrichi, M., Camacho, L., Russell, D. G. \& DeLisa, M. P. Genetic toggling of alkaline phosphatase folding reveals signal peptides for all major modes of transport across the inner membrane of bacteria. J. Biol. Chem. 283, 35223-35235 (2008).

29. Zoufaly, S. et al. Mapping precursor-binding Site on TatC subunit of twin arginine-specific protein translocase by site-specific Photo cross-linking. J. Biol. Chem. 287, 13430-13441 (2012).

30. Strauch, E. M. \& Georgiou, G. Escherichia coli tatC mutations that suppress defective twin-arginine transporter signal peptides. J. Mol. Biol. 374, 283-291 (2007).

31. Gohlke, U. et al. The TatA component of the twin-arginine protein transport system forms channel complexes of variable diameter. Proc. Natl Acad. Sci. USA 102, 10482-10486 (2005).

32. White, G. F. et al. Subunit organization in the TatA complex of the twin arginine protein translocase: a site-directed EPR spin labeling study. J. Biol. Chem. 285, 2294-2301 (2010).

33. Frielingsdorf, S., Jakob, M. \& Klösgen, R. B. A stromal pool of TatA promotes Tat-dependent protein transport across the thylakoid membrane. J. Biol. Chem. 283, 33838-33845 (2008).

34. Schlesier, R. \& Klösgen, R. B. Twin arginine translocation (Tat)-dependent protein transport: the passenger protein participates in the initial membrane binding step. Biol. Chem. 391, 1411-1417 (2010).

35. Bageshwar, U. K., Whitaker, N., Liang, F. C. \& Musser, S. M. Interconvertibility of lipid- and translocon-bound forms of the bacterial Tat precursor pre-SufI. Mol. Microbiol. 74, 209-226 (2009).

36. Brehmer, T. et al. Negatively charged phospholipids trigger the interaction of a bacterial Tat substrate precursor protein with lipid monolayers. Langmuir. 28, 3534-3541 (2012).

37. Barrett, C. M., Freudl, R. \& Robinson, C. Twin arginine translocation (Tat)dependent export in the apparent absence of TatABC or TatA complexes using modified Escherichia coli TatA subunits that substitute for TatB. J. Biol. Chem. 282, 36206-36213 (2007).

38. Baglieri, J., Beck, D., Vasisht, N., Smith, C. J. \& Robinson, C. Structure of TatA paralog, TatE, suggests a structurally homogeneous form of Tat protein translocase that transports folded proteins of differing diameter. J. Biol. Chem. 287, 7335-7344 (2012).

39. Barnett, J. P., Eijlander, R. T., Kuipers, O. P. \& Robinson, C. A minimal Tat system from a gram-positive organism: a bifunctional TatA subunit participates in discrete TatAC and TatA complexes. J. Biol. Chem. 283, 2534-2542 (2008).

40. Blaudeck, N., Kreutzenbeck, P., Müller, M., Sprenger, G. A. \& Freudl, R. Isolation and characterization of bifunctional Escherichia coli TatA mutant proteins that allow efficient Tat-dependent protein translocation in the absence of TatB. J. Biol. Chem. 280, 3426-3432 (2005).

41. Jongbloed, J. D., van der Ploeg, R. \& van Dijl, J. M. Bifunctional TatA subunits in minimal Tat protein translocases. Trends Microbiol. 14, 2-4 (2006).

42. Blaudeck, N., Kreutzenbeck, P., Freudl, R. \& Sprenger, G. A. Genetic analysis of pathway specificity during posttranslational protein translocation across the Escherichia coli plasma membrane. J. Bacteriol. 185, 2811-2819 (2003).
43. Moser, M., Panahandeh, S., Holzapfel, E. \& Müller, M. In vitro analysis of the bacterial twin-arginine-dependent protein export. Methods Mol. Biol. 390, 63-80 (2007).

44. Brondijk, T. H., Nilavongse, A., Filenko, N., Richardson, D. J. \& Cole, J. A NapGH components of the periplasmic nitrate reductase of Escherichia coli $\mathrm{K}-12$ : location, topology and physiological roles in quinol oxidation and redox balancing. Biochem. J. 379, 47-55 (2004).

45. Maurer, C., Panahandeh, S., Jungkamp, A. C., Moser, M. \& Müller, M. TatB functions as an oligomeric binding site for folded Tat precursor proteins. Mol. Biol. Cell 21, 4151-4161 (2010).

46. Lee, P. A. et al. Cysteine-scanning mutagenesis and disulfide mapping studies of the conserved domain of the twin-arginine translocase TatB component. J. Biol. Chem. 281, 34072-34085 (2006).

47. Gerard, F. \& Cline, K. The thylakoid proton gradient promotes an advanced stage of signal peptide binding deep within the Tat pathway receptor complex. J. Biol. Chem. 282, 5263-5272 (2007).

48. Fincher, V., McCaffery, M. \& Cline, K. Evidence for a loop mechanism of protein transport by the thylakoid Delta $\mathrm{pH}$ pathway. FEBS Lett. 423, 66-70 (1998).

49. Kneuper, H. et al. Molecular dissection of TatC defines critical regions essential for protein transport and a TatB-TatC contact site. Mol. Microbiol. 85, 945-961 (2012).

50. Dalbey, R. E., Wang, P. \& Kuhn, A. Assembly of Bacterial inner membrane proteins. Annu. Rev. Biochem. 80, 161-187 (2011).

51. Whitaker, N., Bageshwar, U. K. \& Musser, S. M. Kinetics of precursor interactions with the bacterial Tat translocase detected by real-time FRET. J. Biol. Chem. 287, 11252-11260 (2012).

52. Fröbel, J., Rose, P. \& Müller, M. Early contacts between substrate proteins and TatA translocase component in twin-arginine translocation. J. Biol. Chem. 286, 43679-43689 (2011).

53. Celedon, J. M. \& Cline, K. Stoichiometry for binding and transport by the twin arginine translocation system. J. Cell Biol. 197, 523-534 (2012).

54. Di Cola, A. \& Robinson, C. Large-scale translocation reversal within the thylakoid Tat system in vivo. J. Cell Biol. 171, 281-289 (2005).

55. Alami, M., Trescher, D., Wu, L. F. \& Müller, M. Separate analysis of twinarginine translocation (Tat)-specific membrane binding and translocation in Escherichia coli. J. Biol. Chem. 277, 20499-20503 (2002).

56. Orriss, G. L. et al. TatBC, TatB, and TatC form structurally autonomous units within the twin arginine protein transport system of Escherichia coli. FEBS Lett. 581, 4091-4097 (2007)

57. Lesley, S. A., Brow, M. A. \& Burgess, R. R. Use of in vitro protein synthesis from polymerase chain reaction-generated templates to study interaction of Escherichia coli transcription factors with core RNA polymerase and for epitope mapping of monoclonal antibodies. J. Biol. Chem. 266, 2632-2638 (1991).

58. Holzapfel, E. et al. Twin-arginine-dependent translocation of Sufl in the absence of cytosolic helper proteins. Biochemistry 48, 5096-5105 (2009).

\section{Acknowledgements}

We gratefully acknowledge Prof. Tracy Palmer for providing plasmid pFAT588 and strain BL21(DE3) $\Delta$ Tat) and Tobias Flecken for helping with the preparation of plasmid pTF1. This work was supported by Sonderforschungsbereich 746 and Forschergruppe 929 of the Deutsche Forschungsgemeinschaft.

\section{Author contributions}

J.F. performed all experiments and prepared the figures; P.R. constructed most of the plasmids; F.L. constructed plasmid p8737-tatAC; A.S.B. provided technical assistance; R. F. provided the original TatB-lacking constructs, initiated and co-designed the project and helped with the preparation of the manuscript; $M$. M. wrote the manuscript and designed the project.

\section{Additional information}

Supplementary Information accompanies this paper on http://www.nature.com/ naturecommunications

Competing financial interests: The authors declare no competing financial interests

Reprints and permission information is available online at http://npg.nature.com/ reprintsandpermissions/

How to cite this article: Fröbel, J. et al. Transmembrane insertion of twin-arginine signal peptides is driven by TatC and regulated by TatB. Nat. Commun. 3:1311 doi: 10.1038/ ncomms2308 (2012).

This work is licensed under a Creative Commons AttributionNonCommercial-NoDerivs 3.0 Unported License. To view a copy of this license, visit http://creativecommons.org/licenses/by-nc-nd/3.0/ 